ACTA POÉTICA 40-1 • ENERO-JUNIO • 2019 • 189-195

doi: 10.19130/iifl.ap.2019.1.851

recepción: 4-VIII-2018 / aceptación: 19-X-2018

ESTHER COHEN (ED.). Glosario WALTER BENJAMIN. CONCEPTOS Y FIGURAS. MÉXICO: INSTITUTO DE INVESTIGACIONES FILOLÓGICAS, 2016.

\title{
Rocío UGALDE
}

Universidad Nacional Autónoma de México

itzel2391@hotmail.com

\begin{abstract}
A tender lo minúsculo, el detalle, el destello breve que descompone el panorama perfecto de la historia o el gesto de cepillar a contrapelo seduce cada vez más para desnormalizar las prácticas de estudio ancladas a una visión de tiempo e historia lineales y progresivos de un relato, que destierra a los vencidos. $Y$ es que la fuerza para estas batallas proviene de los granos de la arena, donde éstas se libran: "desde la aparición de un poema, un trazo arquitectónico, una imagen, un género como el barroco, en la crítica, en la interpretación y en las tareas de traducción" (137). Distintos son los frentes donde entran en acción las tácticas legadas por la maquinaria filosófica de Walter Benjamin (Berlín, 1892- Port Bou, 1940), cuya sensible visión continúa convocando debates y reinterpretaciones. Pese a la accidentada validación en los círculos académicos de su propia época, las revaloraciones y relecturas en los terrenos de la filosofía, la literatura, el cine y las artes, en general, han tenido constantes renovaciones. En esta línea de actividad de rescate se inscribe el Glosario Walter Benjamin, editado por la Dra. Esther Cohen.

Resulta importante subrayar, entonces, los motivos del armado de este libro, pues casi siempre permanecen ajenos para el lector que recibe el artefacto de papel terminado. En el caso de esta publicación, las primeras líneas nos comparten el andamiaje que se despliega en las poco más de trescientas páginas de conceptos y figuras benjaminianas: el resultado de un esfuerzo y decisión colectivos de académicos y estudiantes tras haber dedicado reuniones en distintos tiempos en torno al pensamiento del filósofo judeoalemán, cuyo objetivo principal tiene en la mira la difusión de su contenido en México.
\end{abstract}


Las colaboraciones no se restringen a participantes de la Facultad de Filosofía y Letras o del Instituto de investigaciones Filológicas de la UNAM. El proyecto convocó a investigadores de varios países de Europa y América Latina (London University, Universidad de Chile, Universidad de Guanajuato, Université de Nice, Université de Luxembourg, UFRJ, la Univesität der Künste, Pontifícia Universidade de São Paulo, por ejemplo). La escritura irradia desde más de un estilo ensayístico. Se trata de veinticinco entradas ordenadas alfabéticamente: algunas de ellas redactadas a cuatro manos, otras directamente en español y unas más pasaron por un ejercicio de traslación desde el italiano, el francés, el inglés y del portugués. En su conjunto pretenden ofrecer una guía a los primeros acercamientos al pensamiento benjaminiano, sin que ello excluya a otros lectores mucho más familiarizados con las ideas de este filósofo. El libro cierra con breves presentaciones de diez figuras imprescindibles —el Ángel de la historia, el Coleccionista, la Ruina, la Vasija Rota, por citar algunas-, que condensan visualmente los movimientos de la reflexión benjaminiana, acompañadas de interpretaciones gráficas de Elsa R. Brondo, quien además desarrolla las páginas dedicadas a "Alegoría” y "Fragmento".

Todo intento de presentación se quedaría a medio camino por la naturaleza de esta obra colectiva. La lectura rompe la dirección única, como sucede cuando consultamos un diccionario: permite la entrada y salida del lector que busca comprender un término en específico. La consulta, sin embargo, tiende puentes subterráneos o senderos cruzados, ya que los conceptos que figuran a lo largo del libro reaparecen en más de una ocasión. Algunos de ellos también van imantando, creando pequeños campos gracias a la cercanía semántica o temática. Es imposible dar cuenta de todo el contenido del libro, empero, realizar una selección de unas cuantas entradas, podría dar pistas de lo que reconstruyen los autores e ilustradora.

Del viaje emprendido por la prosa de Benjamin y su recepción en terrenos hispanohablantes, la mediación lingüística no siempre llama suficientemente la atención. He aquí una de las principales contribuciones que arrojan luz sobre el mecanismo revolucionario de los conceptos enlistados. La interpretación a partir del español exige en reiteradas ocasiones obviar la palabra exacta que aparece en el texto fuente. En ese retorno al alemán, algunos autores del volumen enfocan las grietas lingüísticas que dejó el desplazamiento traductológico para explicar mejor el sentido de los conceptos.

Por poner un ejemplo, en la familia de palabras ligadas al acto de la memoria, Benjamin habría insertado un uso poco común en la lengua alemana. La entrada "Rememoración/Inmemoración: Eingedenken” parte 
desde el uso excepcional del verbo alemán “Eingedenken", convertido al español como Inmemorar. Stefano Marchesoni nos entrega una invención traductológica interesada en conservar la fuerza estruendosa del término alemán, dado que la simple conversión al español como "rememorar" no deja sobrevivir el trastrocamiento que opera en esta palabra:

[m]ientras que "rememoración" significa literalmente re-memorar, esto es, volver a llamar a la memoria algo que tuvo lugar en el pasado, el término benjaminiano Eingedenken alude a la posibilidad de evocar lo que no tuvo lugar. Éste exige entonces una traducción especial: a la luz de tales consideraciones, se podría traducir Eingedenken con el neologismo ‘inmemorar'. El prefijo "in” aquí no se debe entender como negación (como por ejemplo en el caso de "imposible"), sino como la preposición alemana "ein-", esto es como indicación de movimiento a un lugar (como ocurre en el caso de "inmersión"): el inmemorar como experiencia* de un colapso temporal entre presente y pasado (una "detención" del tiempo que Benjamin Ilamó "Dialektik im Stillstand", esto es, "dialéctica* en estado de suspensión") gracias a la irrupción de lo inmemorial (la oportunidad fallida, lo que no tuvo lugar) en el ahora (188)

Marchesoni indica que no corresponde a un aporte lingüístico inédito. Proviene, en cambio, de un préstamo de la lectura de Ernst Bloch, de la que Benjamin sustrae la implicación política, pero a la que imprime de paso el acto de traer de vuelta el pasado para actualizarlo en el presente, es decir, aquello que "no tuvo lugar". Asimismo, Marchesoni da pistas de la trayectoria diseminada de la inmemoración en las obras del filósofo: los escritos de la infancia berlinesa, entorno a Kraus, Kafka, Baudelaire, la figura del narrador y el texto mayor Sobre el concepto de Historia.

Sigue la recepción y algunas etapas de este aporte conceptual benjaminiano, una de las características generales de cada ensayo del Glosario. A decir de Marchesoni, inmemorar sufrió una suerte de petrificación al ser adoptado ulteriormente por Adorno y Horkheimer; la reapropiación volvió a este verbo un acto más cercano a una actividad contemplativa. Por fortuna, ha ido liberándose de esa interpretación y con el paso del tiempo, más nombres han ido despertando la potencia en reposo de inmemorar: desde Hannah Arendt, Stéphane Mosès, los ensayos del italiano Giorgio Agamben, el francés Georges Didi-Huberman, y una conexión estrecha con el escritor alemán Winfried G. Sebald. El rasgo central de esta entrada reside 
en no dejar la impresión de un pensamiento filosófico estático: "no tiene que ser entendido de manera unívoca, sino como una idea [...] como una constelación formada por conceptos diferentes" (190).

Dentro de esta forma de iluminar y filtrar los ecos de la lengua de Benjamin, en un ejercicio lingüístico similar, Marc Berdet no se aparta al abordar el contenido de "Origen". Como si se tratase de separar para ver mejor, las primeras líneas desdoblan los tres niveles que convierten al término alemán Ursprung en un torbellino: por un lado, la cara de la prehistoria, por el otro, la fase más antropológica que atiende al mito, ese "tiempo originario" sometido al designio exterior de los dioses, y, por último, la temporalidad que osa dar el "salto originario", responsable de liberarse del destino de los dioses. Es ese remolino el que asesta, en realidad, un profundo golpe a la idea del origen condensado visualmente en un punto estático e identificable, al tiempo que arrastra consigo las bases de la historia que emana desde un origen reconocible en constante marcha lineal. La separación de esta tríada que efectúa Berdet brinda mayor claridad sobre la idea temporal e histórica de Benjamin: "el desafío consiste en regresar a la fuente oscura donde brilla asimismo una red de luz, pero sin caer en la oscuridad. Se trata en el fondo de hundirse en la noche del mito para reencontrar ahí el impulso originario. Una vez retomado y transformado, éste nos permitirá entrar en la historia en el pequeño día" (164-165).

Podríamos encadenar, en el mismo tenor, el ensayo de Marianela Santoveña Rodríguez por su capacidad de destejer por un instante los hilos que bordan la concepción del "Tiempo ahora". Acompaña en el título de la entrada su correspondencia en alemán Jetztzeit; dicho término ha recibido la versión de "Tiempo ahora" o "Tiempo actual”. El procedimiento de desenmarañar el quiebre que persigue derribar los cimientos de la temporalidad propia de la Modernidad reside en el contraste de dos conjuntos tripartitos. El primero ilustra el contexto contra el que se rebela Benjamin; es decir, una visión de tiempo fundamentada en: 1) el entrelazamiento animado por la relación de causa-efecto; 2) cuya consecuencia diseña una linealidad progresiva, un "tiempo homogéneo y vacío"; 3) la acumulación de este acomodamiento desemboca indefectiblemente en el hombre al dominio de la naturaleza (229). En oposición, el filósofo alemán imagina una astucia que hace temblar este edificio aparentemente perfecto y lógico del tiempo. En palabras de Santoveña Rodríguez, es posible esclarecerla así: el "Tiempo ahora" nos reclama una escucha atenta de los vencidos, de lo que ha ido acumulándose en el pasado; abre paso a una nueva legibilidad temporal: “1) no funciona por adición, sino por interrup- 
ción; 2) constituye un tiempo "lleno" o imagen total de la historia, por oposición al "tiempo homogéneo y vacío", y 3) no privilegia el dominio sobre la naturaleza a través del tiempo, sino la agencia política de la que nos dota la temporalidad" (231). Por tanto, nuestra relación con el presente se fisura, convertido en el "Tiempo ahora", que está en espera de recuperar los chispazos de un pasado que tradicionalmente yacerían invisibles. Benjamin nos enseñaría una minúscula desobediencia al reloj imparable e irreversible del progreso homogéneo y vacío.

Llegamos a otra palabra clave: "Progreso", que da cuerpo al enemigo a combatir. En esta oportunidad, toma la batuta el mismo autor del conocido título Walter Benjamin: aviso de incendio. Una lectura de las tesis sobre el concepto de historia (2003), el investigador Michael Löwy. Las once páginas nos adentran quizá hacia uno de los puntos neurálgicos responsables que detonan la urgencia de las preocupaciones de Benjamin. El retrato del progreso quedaría mejor plasmado, con base en la descripción de Löwy, en la imagen de una moneda. Si una de las caras pertenece a lo que únicamente queda en la superficie, a saber, el falso camino que conduce al paraíso de un estado cada vez más perfecto, la otra cara oculta forja su diseño con el cúmulo de las derrotas, de la catástrofe. Así, la razón instrumental que iría a la par del progreso culmina en sus últimas consecuencias lógicas en el extremo de lo irracional, cuyo caso emblemático sería la agravante llegada del fascismo.

En ello, Löwy encuentra en Sobre el concepto de historia (1940) uno de los documentos más importantes del pensamiento revolucionario después de Marx y las Tesis sobre Feuerbach (1845). No obstante, lograr este alcance exige tomar impulso con una maniobra sagaz que aproxima tres fuentes para lograr la afrenta al progreso: el romanticismo alemán, el marxismo y el mesianismo judío. Tres ingredientes que pueden repelerse, dan las armas a Benjamin para emprender un pensamiento marxista radical.

La inmersión en las páginas del filósofo judeoalemán pide avanzar con cautela y es allí donde Löwy inserta un par de advertencias contra errores que podrían producirse. Si bien conviene distinguir que todos los autores de este libro puntualizan la transformación o breves esbozos de los conceptos desde los escritos más tempranos hasta la obra póstuma, Löwy enfatiza el gran equívoco de erigir una interpretación que capture la obra de Benjamin ora como una tajante separación entre las ideas de juventud y las últimas obras; ora como un conjunto homogéneo, incapaz de darse cuenta del giro que aportó el marxismo en sus textos. No se trata de forzar el pensamiento benjaminiano y conducirlo a una de estas dos postu- 
ras, sino de acompañar y detectar los matices y mutaciones. La segunda precisión surge de la referencia a los vencidos, que no debe confundirse o asociarse al contexto de los enfrentamientos bélicos, más bien a los choques de clases, que han encumbrado exclusivamente a los vencedores. Se ilumina, pues, un léxico desprendido de los descubrimientos de Benjamin, que marcará un punto de quiebre: el marxismo. Dicha teoría llega a él a través de Asja Lacis acompañada de la lectura de Historia y conciencia de clase de Lukács. De aquí recupera la lucha de clases, tan crucial para el anhelo de liquidar el progresismo de su época. El lado que elige salvar de ese choque de clases es el de los vencidos.

Löwy no pasa por alto dos fuentes más que fortalecen el arsenal teórico benjaminiano, en un gesto por brindar un contexto más general dentro del ambiente de la filosofía. De Nietzsche, Benjamin desentierra la burla por la admiración del éxito y los vencedores mientras que del comunista Pierre Naville extrae la "organización del pesimismo". Ante el optimismo del progreso, Benjamin supo contraponer, escribe Löwy, un pesimismo activo en perpetua desconfianza, cuya magnitud pueda aniquilar el culto al progreso. Entre algunos apuntes minuciosos, esta entrada, como sucede en otras páginas, ofrece asimismo las resistencias o reticencias de algunos lectores de Benjamin. El ejemplo de Löwy alude a la opinión de Habermas en relación con el equívoco metodológico benjaminiano de hacer coincidir la filosofía de la historia antievolucionista con el materialismo histórico: "Eso que Habermas concibe como un error es precisamente la fuente del valor singular de la filosofía benjaminiana de la historia y de su capacidad para comprender un siglo caracterizado por la imbricación estrecha entre el progreso moderno y la barbarie" (185).

Este tipo de tensiones que nunca logra una síntesis total son las que retan a re-interpretar esos "desaciertos" del ingenio de Walter Benjamin. Es el caso de "Mesianismo" reconstruido por Esther Cohen. La amistad que Benjamin mantuvo con Gershom Sholem, especialista del misticismo judío, le transmitió elementos de lo sagrado, que tiemblan al entrar en contacto con una aplicación profana: "este concepto de mesianismo no sólo se refiere a un futuro utópico, a la espera pasiva del arribo de Mesías, sino más bien a la posibilidad de rescatar un pasado oprimido a través de un proceso revolucionario" (137). Figura que nos podría incomodar por su origen religioso, el Mesías daría la impresión de ser un disparate en los terrenos filosóficos. Sin embargo, su uso dista de ello. Una vez más, la distancia tan corta entre dos polos opuestos —esta vez lo divino y lo profano-representa un desafío inherente a la fuerza radical de Walter Benjamin. 
Como hemos adelantado, continuar con más pormenores de este proyecto colectivo, daría un panorama injusto, empero, otra sugerencia de constelación por afinidades podría formarse a partir de los conceptos más ligados a la literatura, el cine, y la pintura: "Crítica", "Montaje”, "Fragmento", “Narración”. Un encadenamiento distinto sería "Violencia”, “Justicia" y "Lenguaje". Ha de reconocerse en esta flexibilidad del Glosario, la valiosa claridad de los ensayos que entablan indirectamente un diálogo entre sí, lo que produce un reforzamiento de las nociones en los recorridos de la lectura. Una virtud más estriba en añadir los lazos que América Latina mantiene con las reflexiones de Walter Benjamin. Prueba de ello es la referencia al libro de Andrés Claro, Las vasijas quebradas desde Chile, en el apartado sobre la "Traducción", desglosada por Eugenio Santangelo o el dato que proporcionan Francisco Naisaht y Senda Sferco a propósito de "Teología”: Conocimiento y redención en la filosofía de Benjamin (2014), de la investigadora argentina Florencia Abadi

Dentro de la labor de difusión, cabe mencionar que las menciones de las obras de Walter Benjamin dan espacio al lector para conocer algunos escritos no tan a menudo citados de la galería benjaminiana: "Sombras breves", "Fragmento teológico-político" (1920-1921), "La vida de los estudiantes” (1914-1915), "Sobre algunos motivos en Baudelaire” (1939), "Eduard Fuchs, coleccionista e historiador" (1937), "El Surrealismo. Última instantánea de la inteligencia europea” (1929). En fin, hacer justicia a cada una de las participaciones se podría traducir en que activan la posibilidad de sacudir algunas interpretaciones estáticas de Benjamin o más canónicas; al mismo tiempo que no caen por completo en el lenguaje extremadamente técnico de interpretaciones que impide la apertura a círculos de nuevos lectores. Este glosario es una invitación a hacernos cargo de la "débil fuerza mesiánica" del pasado.

\section{Rocío UGALDE}

Traductora literaria, licenciada en Letras Francesas por la UNAM y estudiante de maestría en Literatura Comparada en la misma institución. Becaria del Centro Internacional de Traducción Literaria de BANFF, Canadá (2013). Ha traducido La higuera encantada de Marco Micone (UNAM 2014), Las silenciosas Islas Chagos de Shenaz Patel (UNAM 2016). Colaboró en la selección de textos, traducción de varios fragmentos, corrección, revisión y pre-edición de la antología Ausencias y espejismo. Francofonía literaria (FCE 2017). Imparte el seminario de "Introducción a las literaturas francófonas" en la Facultad de Filosofía y Letras en la UNAM. 